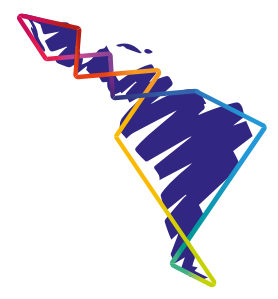

\title{
Apuntes jurisprudenciales: La sentencia del caso Cuscul Piraval y otros Vs. Guatemala, emitida por la Corte Interamericana de Derechos Humanos
}

\author{
Jurisprudential notes: The judgment \\ of the Case of Cuscul Piraval and \\ Others V. Guatemala, issued by the \\ Inter-American Court of Human \\ Rights
}

Alejandro Díaz Pérez

\begin{abstract}
Resumen
La sentencia del caso Cuscul Piraval y otros Vs. Guatemala del 23 de agosto de 2018, emitida por la Corte Interamericana de Derechos Humanos representa la primera condena específica al principio de progresividad. Sin embargo, este avance sustancial en la justiciabilidad de los derechos económicos, sociales y culturales, está acompañado de enormes desafíos que el sistema interamericano aún debe sortear. El presente artículo reflexiona sobre dichos retos a partir del análisis de esta importante resolución.
\end{abstract}

Palabras clave: Corte Interamericana de Derechos Humanos, sentencia, jurisprudencia, obligación de progresividad.

\section{Summary}

The judgement of Case of Cuscul Piraval and Others V. Guatemala of August 23, 2018, issued by the Inter-American Court of Human Rights represents the first specific condemnation of

1 Licenciado en Derecho y Ciencias Sociales, Universidad Michoacana de San Nicolás de Hidalgo. Master en Gobernanza y Derechos Humanos, Universidad Autónoma de Madrid, España. Especialista en Derechos Humanos y Master en Derecho Constitucional, Universidad de Castilla-La Mancha, España. Exvisitante profesional en la Corte Interamericana de Derechos Humanos. Fue abogado del Grupo de Recomendaciones de la Comisión Nacional de los Derechos Humanos (México). 
the principle of progressivity. However, this substantial advance in the justiciability of economic, social and cultural rights is accompanied by enormous challenges yet to be overcome by the Inter-American system. The present article reflects on these challenges by analyzing this important resolution.

Keywords: Inter-American Court of Human Rights; Judgment; Jurisprudence; Obligation of progressivity.

\section{Introducción}

Los mecanismos de justiciabilidad y exigibilidad de los derechos económicos, sociales, culturales y ambientales (DESCA) han sufrido importantes transformaciones para que su concreción práctica sea efectiva.

Los avances con mayor significado sobre los DESCA han sido construidos desde el sistema universal de derechos humanos; sin embargo, a nivel regional, hasta recientemente, tanto la Comisión Interamericana de Derechos Humanos (CIDH), como la Corte Interamericana de Derechos Humanos (Corte IDH) no habían profundizado su jurisprudencia en relación con este tipo de derechos. A partir del fallo Lagos del Campo vs Perú del 31 de agosto del 2017, la Corte IDH rompió su posición predominante, en la que sostenía que los DESCA solo podían abordarse en conexidad con los derechos civiles y políticos, para transitar a una interpretación que sitúa los derechos económicos, sociales y culturales como autónomos y directamente justiciables.

En ese contexto, el presente artículo analiza, en un primer momento, la forma en que se establecieron los primeros avances en la jurisprudencia de la Corte IDH sobre los DESCA, para después centrarse en abordar con detalle la argumentación desarrollada por el Tribunal Interamericano en la sentencia del caso Cuscul Piraval y otros Vs. Guatemala del 23 de agosto de 2018, en la cual declaró, por primera vez en su historia, la violación al principio de progresividad, en tanto el Estado incumplió con su obligación de desarrollo progresivo del derecho a la salud. Posteriormente, se examinan las implicaciones generadas por el voto parcialmente disidente, formulado por el juez Humberto Antonio Sierra Porto. Finalmente, se reflexiona sobre los posibles aspectos que en un futuro los órganos del sistema interamericano -especialmente la Corte IDH- podrían ampliar para fortalecer la protección de los DESCA en la región de las Américas.

\section{Pasos iniciales en la jurisprudencia interamericana sobre los DESCA}

Dentro del sistema interamericano, el parámetro de tutela de los órganos del sistema es la Convención Americana sobre Derechos Humanos (en adelante CADH o 
Convención Americana), tratado que centralmente reconoce derechos civiles y políticos; sin embargo, cabe señalar que este también hace referencia a los derechos económicos, sociales y culturales.

Al respecto, el artículo 26 de la CADH prevé sobre el desarrollo progresivo de los DESCA:

Los Estados Partes se comprometen a adoptar providencias, tanto a nivel interno como mediante la cooperación internacional, especialmente económica y técnica, para lograr progresivamente la plena efectividad de los derechos que se derivan de las normas económicas, sociales y sobre educación, ciencia y cultura, contenidas en la Carta de la Organización de los Estados Americanos, reformada por el Protocolo de Buenos Aires, en la medida de los recursos disponibles, por vía legislativa u otros medios apropiados.

En el mismo sentido, como parte de los avances de reconocimiento, los países de la región, considerando la estrecha relación que existe entre la vigencia de los derechos económicos, sociales y culturales y la de los derechos civiles y políticos, por cuanto constituyen un todo indisoluble, adoptaron el Protocolo Adicional a la Convención Americana sobre Derechos Humanos en materia de derechos económicos, sociales y culturales ("Protocolo de San Salvador") del 17 de noviembre de 1988 .

Partiendo de esas referencias normativas, la Corte IDH, en una aproximación inicial, dotó de cierto nivel de justiciabilidad a los DESCA, principalmente por vía de conexidad con los derechos civiles. De la misma forma, al interpretar de manera amplia el contenido y alcance de las garantías judiciales (artículo 8) y la protección judicial (artículo 25) previstas en la CADH, ha considerado dimensiones de estos derechos en relación con la tutela efectiva de los derechos económicos, sociales y culturales.

Sin embargo, el paso de mayor trascendencia realizado por la Corte IDH ha sido con la sentencia del caso Lagos del Campo vs Perú, en la cual, por primera vez en su historia, dictó una condena específica por la violación del artículo 26 de la Convención Americana, con motivo de la vulneración del derecho al trabajo, en particular de los derechos a la estabilidad laboral y de asociación.

$\mathrm{Al}$ analizar el fondo del caso, dicho Tribunal afirmó su competencia a la luz de la CADH y con base en el principio iura novit curia, para estudiar la petición inicial sobre la afectación de derechos laborales. En ese sentido, la Corte reiteró: 
la interdependencia e indivisibilidad existente entre los derechos civiles y politicos, y los económicos, sociales y culturales, puesto que deben ser entendidos integralmente y de forma conglobada como derechos humanos, sin jerarquía entre sí y exigibles en todos los casos ante aquellas autoridades que resulten competentes para ello. (Corte IDH, 2017, párr. 141)

Este paso significativo fue replicado por la Corte en las sentencias de los casos de los Trabajadores cesados de Petroperú y otros Vs. Perú; San Miguel Sosa y otras Vs. Venezuela; Poblete Vilchis y otros Vs Chile, e inclusive reiterado en su competencia no contenciosa, con la Opinión Consultiva OC-23/17 sobre medio ambiente y derechos humanos (Obligaciones estatales en relación con el medio ambiente en el marco de la protección y garantía de los derechos a la vida y a la integridad personal - interpretación y alcance de los artículos 4.1 y 5.1, en relación con los artículos 1.1 y 2 de la Convención Americana Sobre Derechos Humanos).

\section{Sentencia del caso Cuscul Piraval y otros Vs. Guatemala}

La sentencia del caso Cuscul Piraval y otros vs. Guatemala² representa la sexta condena relacionada con los DESCA. Asimismo, en la línea jurisprudencial de la Corte IDH se instaura como leading case (caso líder), por ser la primera ocasión en la que se declara la violación al principio de progresividad por el incumplimiento de obligaciones inmediatas y progresivas en relación con el derecho a la salud.

El marco fáctico del caso hace referencia a 34 personas que actualmente viven con el virus de inmunodeficiencia humana (VIH) en Guatemala, así como a 15 personas que vivieron con el virus, pero que ya fallecieron, y a sus familiares. Las víctimas eran personas de escasos recursos, contaban con baja escolaridad y vivían en zonas alejadas de las clínicas donde debían recibir atención médica, o eran mujeres embarazadas.

Estas personas sufrían diversas condiciones y contrajeron enfermedades que ocurren con más frecuencia en sujetos con debilidad del sistema inmunitario. Los efectos de su condición como individuos con VIH no les permitieron realizar la mismas actividades cotidianas que desarrollaban previo a su contagio.

Considerando estos hechos, la Corte Interamericana resolvió que el Estado guatemalteco incumplió con su deber de otorgar un tratamiento médico adecuado a las víctimas, lo que permitió que desarrollaran diversas enfermedades y, en algunos casos, fallecieran.

2 La sentencia fue notificada al Estado y hecha pública el 25 de octubre de 2018. 
Por tanto, la Corte IDH encontró responsable al Estado de Guatemala por violar los "derechos a la salud, a la vida, a la integridad personal, a las garantías judiciales y la protección judicial de las víctimas", y determinó que el Estado cometió "actos de discriminación por razón de género" en contra de dos mujeres embarazadas (Corte IDH, 2018, p. 85).

Tomando en cuenta lo anterior, en las líneas siguientes me centraré en la argumentación que el Tribunal Interamericano desarrolló para "declarar la violación al principio de progresividad contenido en el artículo 26 de la Convención Americana, por las alegadas medidas regresivas adoptadas en detrimento de la plena efectividad del derecho a la salud para personas que viven con el VIH en Guatemala" (Corte IDH, 2018, párr. 72).

En una primera aproximación del análisis de justiciabilidad directa de los DESCA, la Corte Interamericana utilizó los métodos de interpretación estipulados en los artículos $31^{3}$ y 32 de "la Convención de Viena sobre el Derecho de los Tratados, y en lo pertinente, las normas de interpretación que se desprenden del artículo 29 de la Convención Americana" (Corte IDH, 2018, párr. 72-73).

De esta forma, desplegó cuatro formas de interpretación, a saber: ii) interpretación literal, ii) interpretación sistemática, iii) interpretación teleológica, y iv) métodos complementarios de interpretación.

Sobre la interpretación literal, consideró que del texto del artículo 26 es posible afirmar que este refiere, precisamente, al deber de los Estados de lograr la efectividad de los derechos que sea posible derivar de la Carta de la OEA. En ese sentido, estimó que "el caso del artículo 26 implica entender que los Estados acordaron adoptar medidas con el objetivo de dar plena efectividad a los derechos reconocidos en la Carta de la OEA" (Corte IDH, 2018, párr. 78) y, en consecuencia, "debe ser entendido como una formulación acerca de la naturaleza de la obligación que emana de dicha norma, y no acerca de la falta de existencia de obligaciones en sentido estricto para los Estados" (Corte IDH, 2018, párr. 79).

En relación con la interpretación sistemática, la cual hace referencia al contexto en que se ubica el artículo 26 de la Convención Americana, la Corte IDH sostuvo que, al dar interpretación a un tratado no solo se toman en cuenta las disposiciones que lo integran, "sino los acuerdos e instrumentos formalmente relacionados con

3 "31. Regla general de interpretación. I. Un tratado deberá interpretarse de buena fe conforme al sentido corriente que haya de atribuirse a los términos del tratado en el contexto de estos y teniendo en cuenta su objeto y fin...". 
éste, como, por ejemplo, la Declaración Americana de los Derechos y Deberes del Hombre" (Corte IDH, 2018, párr. 82-83).

Por ello, a juicio de la Corte, la interdependencia e indivisibilidad de los derechos reconocidos por la Convención Americana niegan cualquier separación, categorización o jerarquía entre derechos para efectos de su respeto, protección y garantía (Corte IDH, 2018, párr. 86). Concluye, al respecto, que "no existen elementos para considerar que, con la adopción del Protocolo de San Salvador ${ }^{4}$, los Estados buscaron limitar la competencia del Tribunal para conocer sobre violaciones al artículo 26 de la Convención Americana” (Corte IDH, 2018, párr. 89).

Sobre la interpretación teleológica, al analizar el propósito de las normas involucradas, en conexión con el objeto y fin del tratado mismo y los propósitos del sistema regional de protección, la conclusión indiscutible es que la Convención Americana tiene como objeto y fin "la protección de los derechos fundamentales de los seres humanos" (Corte IDH, 2018, párr. 92), por tanto, el reconocimiento de los DESCA sería claramente compatible con esa circunstancia.

Finalmente, en cuanto a la utilización de métodos complementarios de interpretación, la Corte IDH hizo una revisión de los trabajos preparatorios de la $\mathrm{CADH}$, encontrando que había un especial énfasis en "dar a los derechos económicos, sociales y culturales la máxima protección compatible con las condiciones peculiares a la gran mayoría de los Estados Americanos" (Corte IDH, 2018, párr. 96), por lo que consideró:

Dichas manifestaciones de los Estados no contradicen la tesis acerca de que el artículo 26 en efecto reconoce derechos, que están sujetos a las obligaciones generales que los Estados tienen en virtud de los artículos 1.1 y 2 de la Convención Americana y que, por ende, son justiciables. (Corte IDH, 2018, párr. 96)

Una vez fijado el criterio de interpretación, la Corte Interamericana reiteró que existen dos tipos de obligaciones que derivan de los DESCA, protegidas por el artículo 26: aquellas de exigibilidad inmediata, y las de realización progresiva. Específicamente sobre la obligación de desarrollo progresivo, explicó que los Estados parte tienen "la obligación concreta y constante de avanzar lo más expedita y eficazmente posible hacia la plena efectividad de dicho derecho, en la medida de sus recursos disponibles, por vía legislativa u otros medios apropiados" (Corte IDH, 2018, párr. 98).

4 Esto, al considerar que el artículo 19.6 del Protocolo de San Salvador establece límites sobre la competencia de la Corte IDH para conocer sobre violaciones a determinados derechos a través del sistema de peticiones individuales. 
Además, prohíbe la inactividad del Estado en su tarea de implementar acciones para la efectiva protección de estos derechos, "sobre todo en aquellas materias donde la ausencia total de protección estatal coloca a las personas ante la inminencia de sufrir un daño a su vida o a su integridad personal" (Corte IDH, 2018, párr. 146).

En vista de lo anterior, considerando la dimensión progresiva de protección de los DESCA, el Tribunal Interamericano consideró demostrado que el Estado de Guatemala, a pesar de contar con una serie de leyes y programas diseñados para la atención de personas que viven con el VIH, no proveyó tratamiento médico antes del año 2004 para garantizar el derecho a la salud de dichas personas.

En consecuencia, la Corte concluyó que "la inacción por parte del Estado, antes del año 2004, constituyó un incumplimiento de las obligaciones estatales en materia de protección progresiva del derecho a la salud, en violación al artículo 26 de la Convención Americana" (Corte IDH, 2018, párr. 147).

El sentido del fallo tiene una importancia central, en tanto fija, con claridad, que un Estado parte de la Convención tiene que adoptar medidas en el tiempo para dotar de los niveles más altos de protección a los derechos económicos, sociales, culturales y ambientales, y hasta el máximo de recursos con que disponga con especial enfoque en grupos que tienen desventaja socioeconómica o algún grado de vulnerabilidad.

Asimismo, implica que la inmovilidad de un Estado o la ausencia de mecanismos y garantías efectivas de progresividad de los derechos a nivel interno pueden generar - por ese hecho- responsabilidad internacional.

Por otra parte, como consecuencia del fallo, la Corte determinó una serie de las siguientes medidas de reparación integral, entre las que pueden destacarse: brindar gratuitamente tratamiento médico y psicológico a las víctimas de violaciones; garantizarles el derecho a la salud y la integridad personal a estas y a sus familiares; adoptar medidas positivas para garantizar la accesibilidad a los centros de salud; implementar mecanismos de fiscalización y supervisión de los servicios de salud; diseñar un mecanismo para mejorar la accesibilidad, disponibilidad y calidad de las prestaciones de salud para personas que viven con el VIH, incluido un tratamiento médico adecuado para mujeres embarazadas que viven con este padecimiento.

Cabe mencionar también, que aunque el fallo de la Corte IDH puede ser considerado como una decisión que tardó en acontecer, del mismo modo puede servir como parámetro de las obligaciones para los Estados parte, que aún no han consolidado 
o desarrollado su normativa a nivel interno, habida cuenta de las complejas asimetrías existentes en los DESCA a nivel continental.

\section{El voto parcialmente disidente del juez Sierra Porto}

No obstante, la sentencia Cuscul Piraval y otros brinda un avance evidente, también debe considerarse que, al interior de la propia Corte Interamericana, la jurisprudencia sobre los DESCA no ha gozado de un consenso unánime. En el presente caso, el juez Humberto Antonio Sierra Porto formuló un voto parcialmente disidente, por el cual se apartó de una buena parte de los razonamientos y conclusiones a las que la Corte llegó.

Esta posición disidente significaría al menos dos cuestiones que merecen una reflexión; por una parte, representa las dificultades prevalecientes en las interpretaciones de los alcances de las obligaciones de los DESCA en la región de las Américas y su posible imprecisión en contraste con lo desarrollado en otros sistemas (como, por ejemplo, en el Universal, con el Pacto Internacional de Derechos Económicos, Sociales y Culturales y los observaciones generales del Comité DESC de la ONU); y por otra, las resistencias existentes aún en ciertas visiones de los derechos humanos, que se basan en tradiciones jurídicas más restringidas de los DESCA, y que representan un intento de mantener "vivo" un debate que parecía del pasado reciente (la justificación sobre la justiciabilidad y exigibilidad de los DESCA).

El voto parcialmente disidente, se centra en el análisis de fondo que realizó la Corte IDH sobre la responsabilidad internacional del Estado por la violación al derecho a la salud y al principio de progresividad. El juez Sierra Porto parte de la idea de que el derecho a la salud, al estar íntimamente vinculado a las afectaciones a los derechos a la vida e integridad personal, resulta "bastante difícil" o inclusive "imposible" de discernir dónde comienza el "ilícito internacional respecto de cada uno de los derechos que se declaran violados" (Sierra, 2018, párr. 5), y por tanto, "innecesario" realizar un análisis autónomo de la violación al artículo 26 de la Convención Americana, en tanto conlleva a una "duplicidad".

Al respecto, este primer argumento desarrollado en el voto es -cuanto menos- discutible. Con el extenso desarrollo existente en distintos sistemas de protección de los derechos humanos e incluso a nivel interno -no solo en países del continente, sino de otras regiones del mundo-, cuesta sostener que el derecho a la salud no guarda casi ninguna diferencia con los derechos a la vida y a la integridad (como efecto final de la violación), habida cuenta de que dicha afirmación desconocería las claras distinciones entre las obligaciones "típicas" relacionadas con estos 
derechos civiles (obligación positiva y obligación negativa) en contraste con las de un derecho social como la salud (disponibilidad, accesibilidad, aceptabilidad y calidad).

Siguiendo con el contenido del voto, en relación con la obligación de progresividad, el juez Sierra manifestó su desacuerdo frente a la conclusión de la Corte IDH relacionada con la "inacción estatal" (sobre el derecho a la salud de la población de personas que viven con el VIH) para determinar si se había menoscabado el contenido del artículo 26 de la Convención Americana, en tanto, a su juicio:

No se estaría vulnerando el derecho a la salud por una regresión, puesto que la infracción a la norma internacional provendría de una inacción estatal a la hora de implementar los DESCA de manera progresiva, es decir de una falta de materialización efectiva del derecho a la salud. (Sierra, 2018, párr. 10)

La articulación de esta idea es bastante confusa, ya que afirma que la violación al derecho a la salud no sería tal por una "regresión", sino se trataría de una "falta de materialización" de ese derecho. Sin embargo, el argumento olvida que el deber de progresividad no solo tiene una cara "negativa", es decir, la de no generar medidas regresivas al derecho en cuestión, sino también implica una faceta "positiva" o la obligación de adoptar acciones para conseguir el disfrute más alto posible del derecho (a la salud).

Finalmente, otra cuestión que merece un análisis con detenimiento es la posición sostenida en el voto particular sobre la forma en que la Corte ordenó "implementar mecanismos de fiscalización y supervisión de los servicios de salud, mejorar la accesibilidad, disponibilidad y calidad de las prestaciones de salud para personas que viven con el VIH” (Sierra, 2018, párr. 11).

En ese sentido, el juez refiere que dicha medida es "inflexible", al considerar la existencia de un "contexto de recursos escasos" en la mayoría de los países de la región de las Américas, donde prevalecen disparidades en cuanto a los recursos disponibles.

[Por ello,] establecer una obligación de garantizar la provisión de antirretrovirales y la demás medicación indicada a toda persona afectada, como obligación de resultados e independiente de cualquier consideración relativa a la razonabilidad de la asignación de recursos, resulta contraria a la naturaleza prestacional del derecho a la salud, así como al rol encomendado a [la] Corte por la Convención Americana. (Sierra, 2018, párr. 6) 
La afirmación sobre la "existencia de un contexto de escasos recursos en la región" plantea un problema inicial: esta se hace desde un nivel muy alto de abstracción. Tampoco aporta datos relevantes sobre tal contexto, como si esta conclusión fuese obvia. Asimismo, no parece tomar en cuenta que -al menos en los países democráticos- la debida garantía y respeto de los derechos humanos sería una de las prioridades fundamentales de los Estados constitucionales contemporáneos y, por ende, cualquier política de gasto público debería considerar esa primacía de los derechos sobre otras actividades estatales.

En todo caso, cabe enfatizar que la noción "hasta el máximo de los recursos de que disponga" debe entenderse no solo en relación con los recursos financieros existentes a nivel interno, sino también a los que pone a disposición del Estado la comunidad internacional mediante la cooperación y la asistencia internacionales, por lo que, cuando se afirme que un Estado no ha adoptado medidas hasta el máximo de los recursos que se disponga, debe examinarse detenidamente las medidas legislativas o de otra índole que se hayan realizado (Díaz, 2019).

Para determinar si esas medidas son adecuadas o razonables, el Comité DESC de la $\mathrm{ONU}$ ha aclarado que debe considerase al menos lo siguiente: a) hasta qué punto las medidas adoptadas fueron deliberadas, concretas y orientadas al disfrute de los derechos económicos, sociales y culturales; b) si el Estado parte ejerció sus facultades discrecionales de manera no discriminatoria y no arbitraria; c) si la decisión se ajustó a las normas internacionales de derechos humanos; d) en caso de que existan varias opciones en materia de normas, si el Estado se inclinó por la opción que menos limitaba los derechos reconocidos en el Pacto Internacional de Derechos Económicos, Sociales y Culturales; e) el marco cronológico en que se adoptaron las medidas; y f) si las medidas se adoptaron teniendo en cuenta la precaria situación de las personas y los grupos desfavorecidos y marginados, y si se dio prioridad a las situaciones graves o de riesgo (ONU, 2007, párr. 8).

En vista de lo anterior, el presente caso el Estado de Guatemala tuvo la oportunidad de exponer pruebas relacionadas sobre algún posible impedimento de sus recursos a nivel interno. Esto resulta indispensable, ya que alegar-sin más- que un Estado "no cuenta con recursos disponibles" o suficientes para justificar cualquier incumplimiento de obligaciones de derechos humanos, vaciaría de algún modo el sentido de estas mismas, lo cual las desnaturalizaría en tan alto grado que podría debilitar seriamente la protección de los DESCA. 


\section{Reflexiones finales}

Resulta indiscutible la relevancia que representa, para la justiciabilidad de los DESCA en las Américas, el cambio de rumbo que ha tomado la Corte Interamericana en su jurisprudencia sobre el tema.

También debe reconocerse que dicha evolución, francamente, ha tardado en llegar, y el sentido de los fallos se alinean a otros precedentes ya existentes en varios países de la región a nivel interno ${ }^{5}$ incluso tiene menor profundidad comparada con otros desarrollos de órganos internacionales de derechos humanos ${ }^{6}$. Sin perjuicio de lo anterior, no debe perderse de vista que el sistema interamericano se rige bajo el principio de subsidiariedad.

Por otra parte, aunque aún existen posiciones disidentes al interior del Tribunal, la posición mayoritaria ha "derrotado" y eliminado cualquier duda sobre la justiciabilidad de los DESCA en el sistema interamericano, lo que representa un triunfo jurídico y simbólico a destacar.

Pero, el reto de mayor trascendencia de la Corte IDH, en relación con su sistema de precedentes o línea jurisprudencial, debe ser el fortalecimiento de otro tipo de derechos económicos, sociales y culturales, que son de especial complejidad en su desarrollo, como el derecho a vivienda adecuada ${ }^{7}$, a la alimentación, a un nivel de vida digno o los efectos de las actividades empresariales en los DESCA, entre otros.

Asimismo, un aspecto interesante de la jurisprudencia podría ser ajustar el mecanismo de razonamiento de subsunción de los derechos y realizarse a la inversa. Declarar la violación directa - por ejemplo- del derecho a la salud (cuando la circunstancia del caso lo amerite), vía el artículo 26 de la CADH, y las afectaciones que impacten en otros derechos como la vida o a la integridad se invoquen de manera subsuntiva al derecho principal (que sería un DESCA). En principio no existiría ningún impedimento relevante para llevar a cabo este ejercicio de argumentación ${ }^{8}$.

5 En México a nivel interno, la Comisión Nacional de los Derechos Humanos ha emitido decisiones paradigmáticas sobre el contenido de los DESCA, especialmente sobre el derecho a la salud. Al respecto, puede consultarse la Recomendación 18/2016, caso en el que ese órgano consideró incumplidas cuatro obligaciones básicas con respecto a al derecho a la salud (disponibilidad, accesibilidad, aceptabilidad y calidad).

6 Por ejemplo, el Comité de Derechos Económicos, Sociales y Culturales de la ONU.

7 Para una visión más amplia de los obstáculos de justiciabilidad que el derecho a una vivienda adecuada tiene tanto a nivel internacional como doméstico, puede consultarse: "Los mecanismos de exclusión al derecho a una vivienda adecuada en México" (Diaz y Orizaga, 2019).

8 Esto a pesar que, desde luego la parte agraviada durante el procedimiento -primero- ante la Comisión Interamericana de Derechos Humanos y -luego- ante la Corte IDH, plantea aquellos derechos humanos que a su consideración le han sido lesionados, y en consecuencia dichos órganos tienen la obligación de pronunciarse sobre la procedencia de su violación. 
En suma, a pesar de que el avance conseguido por la sentencia del caso Cuscul Piraval y otros vs Guatemala, aunado a los precedentes sobre DESCA, son centrales, aún no se han alcanzado los estándares más altos en varios de estos derechos. Su insondable fortalecimiento, constituirá uno de los avances comunitarios y civilizatorios más representativos de las sociedades contemporáneas en nuestra región americana que hoy -lamentablemente- se caracteriza por sus profundas desigualdades.

\section{Referencias}

Díaz, A. (Enero-junio, 2019). Reflexiones sobre la protección no judicial del derecho a la salud. Revista Latinoamericana de Derecho Social, 28, 35-70 IIJUNAM.

Díaz, A. y Orizaga, A. (Enero-junio, 2019). Los mecanismos de exclusión al derecho a una vivienda adecuada en México. Revista Especializada en Investigación Jurídica, 3(4), 184-206. Centro de Investigaciones Jurídicas de la Universidad Autónoma de Ciudad Juárez.

Corte Interamericana de Derechos Humanos. (2017). Caso Lagos del Campo Vs. Perú. Excepciones preliminares, fondo, reparaciones y costas. Sentencia de 31 de agosto de 2017.

Corte Interamericana de Derechos Humanos. (2018). Caso Cuscul Pivaral y otros vs. Guatemala. Excepción preliminar, fondo, reparaciones y costas. Sentencia de 23 de agosto de 2018.

Corte Interamericana de Derechos Humanos. (2018). Voto concurrente del Juez Humberto Antonio Sierra Porto. Caso Cuscul Pivaral y otros Vs. Guatemala. Excepción preliminar, fondo, reparaciones y costas. Sentencia de 23 de agosto de 2018.

ONU. Comité de Derechos Económicos, Sociales y Culturales. (21 de septiembre, 2007). Declaración sobre la evaluación de la obligación de adoptar hasta el máximo de los recursos de que disponga, de conformidad con un protocolo facultativo del Pacto. Autor. 